\title{
Peak oxygen uptake and left ventricular ejection fraction, but not depressive symptoms, are associated with cognitive impairment in patients with chronic heart failure
}

\author{
This article was published in the following Dove Press journal: \\ International Journal of General Medicine \\ 21 December 201। \\ Number of times this article has been viewed
}

\author{
Gerrit Steinberg ${ }^{1,2^{*}}$ \\ Nicole Lossnitzer ${ }^{2 *}$ \\ Dieter Schellberg ${ }^{2}$ \\ Thomas Mueller-Tasch ${ }^{2}$ \\ Carsten Krueger ${ }^{3}$ \\ Markus Haass ${ }^{4}$ \\ Karl Heinz Ladwig ${ }^{5}$ \\ Wolfgang Herzog ${ }^{2}$ \\ Jana Juenger ${ }^{2}$ \\ 'University Hospital of Psychiatry, \\ University of Bern, Bern, Switzerland; \\ ${ }^{2}$ Department of Psychosomatic \\ and General Internal Medicine, \\ Medical Hospital, University of \\ Heidelberg, Heidelberg, ${ }^{3}$ Department \\ of Cardiology, Josefs Hospital, \\ Heidelberg, ${ }^{4}$ Department of \\ Cardiology, Theresien Hospital, \\ Mannheim, Institute of Epidemiology, \\ German Research Center for \\ Environmental Health, Munich, \\ Germany \\ *both authors contributed equally \\ to this paper
}

Correspondence: Jana Juenger Department of Psychosomatic and General Internal Medicine, Medical Hospital, University of Heidelberg, Im Neuenheimer Feld 4I0, 69I20 Heidelberg, Germany

Tel +4962 21568660

Fax +49622156 I34I

Email jana.juenger@med.uni-heidelberg.de
Background: The aim of the present study was to assess cognitive impairment in patients with chronic heart failure (CHF) and its associations with depressive symptoms and somatic indicators of illness severity, which is a matter of controversy.

Methods and results: Fifty-five patients with CHF (mean age $55.3 \pm 7.8$ years; $80 \%$ male; New York Heart Association functional class I-III) underwent assessment with an expanded neuropsychological test battery (eg, memory, complex attention, mental flexibility, psychomotor speed) to evaluate objective and subjective cognitive impairment. Depressive symptoms were assessed using the Structured Clinical Interview for Diagnostic and Statistical Manual of Mental Disorders, Fourth Edition (SCID) and a self-report inventory (Hospital Anxiety and Depression Scale [HADS]). A comprehensive clinical dataset, including left ventricular ejection fraction, peak oxygen uptake, and a 6-minute walk test, was obtained for all patients. Neuropsychological functioning revealed impairment in $56 \%$ of patients in at least one measure of our neuropsychological test battery. However, the Mini Mental State Examination (MMSE) could only detect cognitive impairment in $1.8 \%$ of all patients, $24 \%$ had HADS scores indicating depressive symptoms, and $11.1 \%$ met SCID criteria for a depressive disorder. No significant association was found between depressive symptoms and cognitive impairment. Left ventricular ejection fraction was related to subjective cognitive impairment, and peak oxygen uptake was related to objective cognitive impairment.

Conclusion: Cognitive functioning was substantially reduced in patients with CHF and should therefore be diagnosed and treated in routine clinical practice. Caution is advised when the MMSE is used to identify cognitive impairment in patients with CHF.

Keywords: chronic heart failure, cognitive impairment, neuropsychological testing, depressive symptoms, peak oxygen uptake, quality of life

\section{Introduction}

Chronic heart failure (CHF) is a frequent complication of heart disease, and is one of the main causes of hospitalization, morbidity, and mortality in Western society. ${ }^{1}$ Clinically, significant depression is present in at least one in five patients with heart failure. ${ }^{2}$ Depression has high rates in both inpatient and outpatient settings, and predicts mortality. ${ }^{3,4}$ Quality of life is often also impaired in patients with $\mathrm{CHF}^{5,6}$ A frequently neglected aspect of the clinical picture in patients with $\mathrm{CHF}$ is their cognitive functioning. ${ }^{7,8}$ Not only does cognitive impairment interfere with the patient's performance of everyday activities, but also with the ability to adhere to a complex 
medication regimen and dietary therapies. Recent findings in patients with CHF have suggested structural brain injury in areas involved in cognitive, language, pain, and mood function. ${ }^{9}$ Although several reports ${ }^{10,11}$ indicate that a considerable number of patients with CHF (20\%-80\%, depending on age) display deficits in cognitive abilities, the determinants and mechanisms of these deficits are not clear due to the paucity of systematic investigations. ${ }^{12,13}$ Until now, most of the relevant studies have only included small or geriatric samples, or focused on patients with end-stage heart failure in New York Heart Association (NYHA) functional class IV. ${ }^{8,14}$ Furthermore, the findings remain controversial. ${ }^{8,15}$

Some of the controversies in this field pertain to a lack of evidence as to the pathophysiology of cognitive impairment in CHF. The current hypotheses for cognitive impairment in heart failure include structural and functional changes in the brain related to vascular events due to emboli, cerebral hypoperfusion, and impaired cerebral vascular reactivity. ${ }^{16-18}$ Several groups, including Woo et al, have reported that patients with heart failure have significantly less gray matter volume than healthy subjects in specific regions of the brain. ${ }^{19}$ Moreover, Siachos et al reported that the prevalence of silent strokes in patients with heart failure was $34 \%,{ }^{20}$ and other investigators found functional changes in patients showing significant reductions in regional blood flow compared with healthy subjects. ${ }^{21}$

However, the associations of cognitive functioning with cardiac output found in the literature are inconsistent. Whereas several investigators ${ }^{11,22,23}$ have noted that neuropsychological scores are not associated with cardiac output, other researchers have reported a significant association between cognitive functioning and left ventricular ejection fraction (LVEF). ${ }^{24}$ Because cognitive impairment may also occur secondary to depressive symptoms or other psychiatric problems, the relationship between depressive symptoms, cognitive functioning, and somatic indicators of illness severity (ie, LVEF, peak oxygen uptake, and walking distance) in patients with CHF is of utmost importance in this area of research. ${ }^{8,15}$ However, only a few investigators have directly assessed cognitive performance and its association with depressive symptoms and somatic indicators of illness severity in patients with $\mathrm{CHF} .{ }^{15}$ Trojano et al, for example, demonstrated a predictive effect of depressive symptoms on neuropsychological performance in geriatric patients using the Geriatric Depression Scale. ${ }^{10}$ In contrast, Strauss et al did not find any associations between depressive symptoms and cognitive impairment in older patients with $\mathrm{CHF}^{25}$ Only Bornstein et al, evaluating 62 patients with end-stage CHF, noted a weak but significant association between depressive symptoms and cognitive impairment $(r=0.29, P<0.02) .{ }^{14}$
In light of the important clinical relevance of this topic, we assessed cognitive impairment in a sample of middleaged patients with CHF (NYHA functional class I-III) using an expanded neuropsychological test battery and evaluated the specific associations between cognitive impairment, clinically significant depressive symptoms, and clinical parameters of CHF. Our first hypothesis was that, compared with standard indications derived from data in healthy controls, the performance of patients with CHF on neuropsychological tasks would be impaired. Our second hypothesis was that cognitive impairment in patients with $\mathrm{CHF}$ would be associated with depressive symptoms, clinical parameters of $\mathrm{CHF}$, and quality of life variables.

\section{Materials and methods}

\section{Sample}

The study was based on analysis of 55 patients (mean age $55.3 \pm 7.8$ years, 44 males, 11 females) with stable CHF, ie, NYHA functional class I-III. Patients were recruited consecutively. Inclusion criteria were stable documented $\mathrm{CHF}$ and $\mathrm{LVEF} \leq 45 \%$. Patients who had neurological and known psychiatric problems including overt dementia were excluded, as were those who had orthopedic, peripheral vascular, renal, or severe pulmonary diseases which could impair successful completion of submaximal or maximal exercise tests. Of 885 screened patients, only 64 were recruited because of a large majority of the patients being ineligible due to LVEF $>45 \%$ or unstable clinical status. The dropout rate, which includes $4 \%$ of missing data, was $15 \%$ (patients became clinically unstable or developed illnesses, or were not available for complete testing). In the end, we had the complete data of 55 patients for our analyses. To obtain an estimate of the required sample size, we assumed that in a full multiple regression model with independent variables of LVEF, peak oxygen uptake, walk test, and HADS depression score, an $R^{2}$ of about 0.2 would be obtained. Additionally we assumed a reduced model that contained three irrelevant independent variables. With $80 \%$ power and an alpha of 0.05 , 45 cases would be necessary to obtain a squared semipartial correlation of the relevant independent variable of 0.2 with the criterion, which is equivalent to the difference between the full and reduced models. Sample size estimation was performed using SAS (v 9.2; SAS Institute Inc, Cary, NC).

\section{Setting}

The patients were referred to the Department of Cardiology at the University Hospital of Heidelberg, Germany. Assessment and examination procedures were conducted within 
4 weeks of initial screening and assessment. Each patient's history, clinical status, sociodemographic variables, and the etiology of heart failure were assessed. Cardiopulmonary exercise testing (peak oxygen uptake), assessment of LVEF, and a 6-minute walk test were conducted on the same day. In order to avoid exhaustion, testing for cognitive functioning and depressive symptoms was either done on the same day, before the clinical tests, or on another day. Short Form (SF)-36 questionnaires were sent to the patients and returned by mail. Recruitment, neuropsychological testing, and assessment of depression were carried out by GS and $\mathrm{MB} ; 15 \%$ of the patients were retested separately by GS and $\mathrm{MB}$, and interrater reliability was satisfactory. Procedures to assess indicators of illness severity (equilibrium radionuclide ventriculography, cardiopulmonary exercise testing, 6-minute walk test) were carried out by medical staff and trained physicians in the department. Ethical approval for the study was obtained from the institutional review board at the Medical Faculty, University of Heidelberg. All the patients gave their written informed consent.

\section{Assessment of cognitive impairment}

All participants were evaluated with a battery of neuropsychological tests designed to assess orientation, verbal and digit memory, complex attention, visuomotor skills, concept formation, language functioning, praxis, calculation, cognitive and motor speed, and mental flexibility. The German versions of the battery of tests included the Trail Making Test $\mathrm{A},{ }^{26}$ a Verbal Learning List, ${ }^{27}$ a digit symbol test, ${ }^{27}$ and a digit recall procedure. ${ }^{28}$ The Trail Making Test A, the Verbal Learning List, and the digit symbol test were administered in two versions, one of them adapted to subjects aged 55 years or older. Additionally, the Mini Mental State Examination (MMSE) was administered to all participants. ${ }^{29}$ The Cerebral Insufficiency Self Report Inventory (CIS) was used to assess subjective cognitive impairment (SCI) by 38 "yes or no" items referring to difficulties in everyday activities. ${ }^{30}$ A score of 20 or more indicates cognitive impairment. All tests produce valid and reliable measures of general cognitive abilities. ${ }^{26-30}$

\section{Assessment of depression}

The Structured Clinical Interview for Diagnostic and Statistical Manual of Mental Disorders, Fourth Edition (SCID) ${ }^{31,32}$ served as the criterion for a depressive disorder. In addition, depressive symptoms were evaluated by the German version of the Hospital Anxiety and Depression Scale (HADS), a selfrating inventory using seven items to assess for depressive symptoms. ${ }^{33}$ A total score $\geq 8$ indicates clinically significant depressive symptoms. This instrument was chosen over other scales assessing depressive symptoms because of minimal item overlap between items referring to somatic symptoms and items referring to heart failure. The HADS scale is a well established self-report inventory to assess depressive symptoms, and has proven to have good operating characteristics. ${ }^{34}$ The average time taken to assess cognitive functioning and depressive symptoms was about 50 minutes.

\section{Assessment of health-related quality of life}

Patient self assessment of health-related quality of life was measured by the German version of the SF-36. ${ }^{35}$ The SF-36 is a generic multidimensional instrument consisting of eight scales representing physical functioning, role functioning physical, bodily pain, general health perceptions, vitality, social functioning, role functioning emotional, and mental health. SF-36 scores are converted to a scale of 0-100, with higher scores indicating a better quality of life.

\section{Assessment of somatic indicators of illness severity}

To determine LVEF, equilibrium radionuclide ventriculography was performed with a multicrystal gamma camera in the left anterior oblique view. Cardiopulmonary exercise testing was used to determine the functional capacity of the subjects. Equipment included a metabolic cart with an interfaced supine positioned bicycle ergometer. Peak oxygen uptake was defined as the maximum oxygen consumption measured during the last 30 seconds of symptom-limited exercise. Submaximal exercise capacity was evaluated with the 6-minute walk test within 24 hours, and at least 4 hours before cardiopulmonary exercise.

\section{Statistical analyses}

In a first step, neuropsychological test battery scores were transformed into $\mathrm{z}$ values adapted for age and education. All z scores $\leq-0.8$ were classified as cognitive impairments. Pearson's correlation coefficients were computed for the relationship between neuropsychological scores, clinical variables (LVEF, peak oxygen uptake, walking distance in the 6-minute walk test), depression (HADS), and quality of life scores (SF-36). Additionally, 95\% confidence intervals were estimated for the mean. Chi-square tests (HADS, total score $\geq 8$ as cutoff) with Bonferroni's correction for multiple comparisons and $t$-tests (SCID) were used to compare the neuropsychological data of depressed and nondepressed patients. 
In a second step, two regression analyses were conducted, with the dependent variables being objective and subjective cognitive impairment. Depression (HADS), peak oxygen uptake, LVEF, and walking distance were used as independent variables.

The objective cognitive impairment variable was generated by a factor analysis of all scores from the neuropsychological battery of tests. Factor analysis was computed with varimax rotation, and the factors could easily be interpreted as reflecting the Verbal Learning List, Trail Making Test A, and Digit Symbol Test. We used principal component analysis. Two factors were retained by the Eigenvalues $>1$ criterion. Varimax rotation showed a factor with high loadings on the Verbal Learning List, Trail Making Test A, and Digit Symbol Test. Because completion of the Digit Symbol Test did not always correspond to completion of the Trail Making Test A and Verbal Learning List, we decided to compute the unweighted sum of the Verbal Learning List and Trail Making Test A as a summary measure for objective cognitive impairment (OCI). The CIS summary score was used for the subjective cognitive impairment variable. Statistical analyses were performed using SAS (v 6.0).

\section{Results}

Demographic data and clinical parameters for all patients are shown in Table 1. Eighty percent of the patients were male and had a cardiological diagnosis of dilated cardiomyopathy $(60.0 \%)$ or coronary artery disease $(23.6 \%)$. Their mean LVEF was $22.4 \% \pm 12.8 \%$, and $61.8 \%$ had NYHA class II, $35.5 \%$ had NYHA class III, and 7.3\% had NYHA class I symptoms. None of the patients was in NYHA class IV. Mean peak oxygen uptake was $14.3 \pm 5.2 \mathrm{~mL} / \mathrm{min} / \mathrm{kg}$.

The prevalence of cognitive impairment (as defined by the tests) in at least one measure of the objective neuropsychological battery of tests (OCI) was $43.6 \%$ compared with normative values reported for healthy adults. ${ }^{26-30}$ Forty percent of the patients reported SCI. Altogether, 56\% of the patients showed deficits in their cognitive capacity in at least one objective or subjective measure (OCI and/ or SCI), $31 \%$ in at least two instruments, and $11 \%$ in three instruments. Thirteen percent showed subjective deficits but no objective impairment. Most deficits occurred in the Verbal Learning List and the Trail Making Test A, indicating impairment in complex attention, verbal memory, and cognitive and psychomotor speed. Single test measures and prevalences of cognitive impairment are shown in Tables 2 and 3.

In contrast with the other measures of our neuropsychological test battery, the MMSE detected cognitive deficits in
Table I Demographic and clinical characteristics of patients

\begin{tabular}{|c|c|}
\hline $\mathrm{n}$ & 55 \\
\hline Age (years) & $55.3 \pm 7.8$ \\
\hline Males/females (\%) & $80.0 / 20.0$ \\
\hline Education $\geq 8$ years $(\%)$ & 54.5 \\
\hline Body mass index $\left(\mathrm{kg} / \mathrm{m}^{2}, \mathrm{SD}\right)$ & $23.8 \pm 8.6$ \\
\hline \multicolumn{2}{|l|}{ Cardiological diagnosis (\%) } \\
\hline Dilated cardiomyopathy & 60.0 \\
\hline Coronary artery disease & 23.6 \\
\hline Others & 16.4 \\
\hline \multicolumn{2}{|l|}{ NYHA functional class (\%) } \\
\hline Class I & 7.3 \\
\hline Class II & 61.8 \\
\hline Class III & 35.5 \\
\hline Class IV & 0.0 \\
\hline $\mathrm{pVO}_{2}(\mathrm{~mL} / \mathrm{min} / \mathrm{kg} ;$ mean, $\mathrm{SD})$ & $14.3 \pm 5.2$ \\
\hline LVEF (\%; mean, SD) & $22.4 \pm 12.8$ \\
\hline 6-minute walk test (mean, SD) & $473.4 \pm 122.3$ \\
\hline SCID, current depressive disorder (\%) & 11.1 \\
\hline HADS $\geq 8(\%)$ & 25.0 \\
\hline \multicolumn{2}{|l|}{ SF-36 (\%, SD) } \\
\hline Role functioning physical & $37.2 \pm 42.3$ \\
\hline General health perceptions & $39.5 \pm 17.3$ \\
\hline Vitality & $41.5 \pm 20.4$ \\
\hline Physical functioning & $48.1 \pm 24.5$ \\
\hline Role functioning emotional & $54.6 \pm 45.3$ \\
\hline Mental health & $60.2 \pm 19.6$ \\
\hline Bodily pain & $64.4 \pm 29.2$ \\
\hline Social functioning & $71.0 \pm 23.9$ \\
\hline Total score & $52.1 \pm 21.0$ \\
\hline
\end{tabular}

Abbreviations: $\mathrm{LVEF}$, left ventricular ejection fraction; $\mathrm{PVO}_{2}$, peak oxygen uptake; NYHA, New York Heart Association; SCID, Structured Clinical Interview for Diagnostic and Statistical Manual of Mental Disorders, Fourth Edition; HADS, Hospital Anxiety and Depression Scale; SD, standard deviation; SF-36, Short Form 36.

only $1.8 \%$ of the patients. There was no significant difference between neuropsychological outcomes in patients with dilated cardiomyopathy, coronary artery disease, and other etiologies of CHF (all $P \geq 0.05$ ).

Using the DSM IV criteria for depressive disorders, $11.1 \%$ of the interviewed patients met the criteria for a current depressive disorder, $20 \%$ for a former depressive episode, and $25 \%$ met the diagnostic criteria for clinically significant depressive symptoms according to the HADS (total score $\geq 8$ as cutoff).

Correlation analyses revealed that higher subjective cognitive impairment was associated with lower scores on the SF-36 subscale of General Health Perceptions $(r=-0.44$; $P<0.01)$. No other significant correlations were found between the SF-36 subscales and the neuropsychological tests. High and significant correlations $(P<0.001)$ were found between depressive symptoms (HADS) and quality of life variables (SF-36), ie, mental health $(r=-0.74)$, total score $(r=-0.70)$, social functioning $(r=-0.68)$, general 
Table 2 Prevalence in cognitive impairment

\begin{tabular}{ll}
\hline Deficits in & \\
One test of $5(\mathrm{OCl}$ or $\mathrm{SCl})$ & $56.0 \%$ \\
Two tests out of $5(\mathrm{OCl}$ and/or SCl$)$ & $31.0 \%$ \\
Three tests out of $5(\mathrm{OCl}$ and/or SCl) & $11.0 \%$ \\
One test out of $4(\mathrm{OCl})$ & $43.6 \%$ \\
SCl, no OCl & $13.0 \%$ \\
Deficits in & \\
Verbal Learning List $(\mathrm{OCl})$ & $23.6 \%^{\mathrm{a}}$ \\
TMT-A (OCl) & $20.0 \%^{\mathrm{a}}$ \\
Digit Symbol Test $(\mathrm{OCl})$ & $9.1 \%^{\mathrm{a}}$ \\
Digit Recall $(\mathrm{OCl})$ & $5.6 \%^{\mathrm{a}}$ \\
Cl Self Inventory $(\mathrm{SCl})$ & $40.1 \%^{\mathrm{b}}$ \\
MMSE & $1.8 \%^{\mathrm{c}}$ \\
\hline
\end{tabular}

Notes: ${ }^{a} z$ value $\leq-0.8$; b total score $\geq 20$; 'total score $<24$.

Abbreviations: $\mathrm{OCl}$, objective cognitive impairment; $\mathrm{SCl}$, subjective cognitive impairment; MMSE, Mini Mental State Examination; Cl Self Inventory, Cerebral Insufficiency Self Inventory.

health perceptions $(r=-0.65)$, vitality $(r=-0.62)$, physical functioning $(r=-0.51)$, bodily pain $(r=-0.47)$, role functioning emotional $(r=-0.44)$ and role functioning physical $(r=-0,38)$ (all $P<0.05)$. Regarding neuropsychological performance, depressed and nondepressed patients did not differ significantly (according to SCID diagnosis and HADS score, $t$-tests and Chi-square tests, see Tables 3 and 4).

\section{Regression analyses for $\mathrm{OCl}$}

Univariate analyses revealed that none of the independent variables were significantly associated with OCI (all $P \geq 0.05$, see Table 5). In the multivariate regression model, only peak oxygen uptake was significantly associated with
OCI $(P=0.04, \beta=0.39)$. The depression variable (HADS) was not significantly related to OCI in the univariate or multivariate analyses $(P=0.60$ and 0.94 , respectively).

\section{Regression analyses for $\mathrm{SCl}$}

Univariate analyses revealed that none of the independent variables were significantly associated with SCI (all $P \geq 0.05)$. The multivariate regression model revealed LVEF as being significantly associated with $\mathrm{SCI}(P=0.04, \beta=0.33)$. The depression variable (HADS) was not significantly related to $\mathrm{SCI}$ in the univariate or multivariate analyses $(P=0.71$ and 0.69 , respectively). Altogether, neither the correlation, $t$-tests, Chi-square procedures, nor the univariate or multivariate analyses revealed significant associations between cognitive status and depressive symptoms.

\section{Discussion}

The objectives of this study were to assess cognitive impairment in middle-aged patients with CHF (mean age $55.3 \pm 7.8$ years) using an expanded neuropsychological test battery and to analyze the specific associations between cognitive impairment, depressive symptoms, and clinical variables in these patients. First of all, we found substantially reduced neuropsychological performance in our patients (56\% were impaired in at least one objective or subjective measure compared with normative values for healthy adults) regarding a variety of cognitive domains, such as memory, complex attention, and psychomotor speed. Furthermore, these impairments seem to be independent of CHF etiology,

Table 3 Neuropsychological battery of tests

\begin{tabular}{|c|c|c|c|c|c|c|c|}
\hline $\begin{array}{l}\text { Test } \\
\text { (German version) }\end{array}$ & Domain & $\begin{array}{l}\text { Total group } \\
\text { deficient } \\
\text { test scores } \\
\text { (\%) }\end{array}$ & $\begin{array}{l}\text { Non-depressed (SCID) } \\
\text { z-value/score } \\
\text { M (SD) } \\
n=39\end{array}$ & $\begin{array}{l}\text { Depressed (SCID) } \\
\text { z-value/score } \\
M(S D) \\
n=10\end{array}$ & $t$ & df & $P$ value ${ }^{a}$ \\
\hline $\begin{array}{l}\text { Trail Making Test A } \\
\text { (Zahlen-Verbindungs-Test) }\end{array}$ & $\begin{array}{l}\text { Attention, cognitive } \\
\text { and motor speed }\end{array}$ & $20.0^{\mathrm{b}}$ & $-0.25(0.71)$ & $-0.84(0.80)$ & 2.29 & 47 & 0.03 \\
\hline $\begin{array}{l}\text { Verbal Learning List } \\
\text { (Wortliste) }\end{array}$ & $\begin{array}{l}\text { Immediate and } \\
\text { delayed recall }\end{array}$ & $23.6^{\mathrm{b}}$ & $0.244(1.04)$ & $0.239(0.93)$ & 0.02 & 47 & 0.98 \\
\hline $\begin{array}{l}\text { Digit Symbol Test } \\
\text { (Zahlen-Symbol-Test) }\end{array}$ & $\begin{array}{l}\text { Complex attention } \\
\text { visuo-motor skills }\end{array}$ & $9.1^{b}$ & $0.46(0.73)$ & $-0.07(0.84)$ & 1.98 & 48 & 0.05 \\
\hline $\begin{array}{l}\text { Digit Recall } \\
\text { (Zahlennachsprechen) }\end{array}$ & $\begin{array}{l}\text { Memory, concentration } \\
\text { concept formation }\end{array}$ & $5.6^{\mathrm{b}}$ & $0.43(0.93)$ & $0.24(1.05)$ & 0.56 & 46 & 0.58 \\
\hline $\begin{array}{l}\text { Cerebral Insufficiency Self } \\
\text { Inventory (Cerebrale- } \\
\text { Insuffizienz-Skala) }\end{array}$ & $\begin{array}{l}\text { Subjective cognitive } \\
\text { impairment }\end{array}$ & $40.1^{c}$ & |6.3| (7.53) & 19.8 (5.59) & -1.37 & 47 & 0.18 \\
\hline $\begin{array}{l}\text { Mini Mental State } \\
\text { (Mini-Mental-Status-Test) }\end{array}$ & $\begin{array}{l}\text { Orientation, attention } \\
\text { immediate and delayed } \\
\text { recall, calculation }\end{array}$ & $1.8^{\mathrm{d}}$ & & & & & \\
\hline
\end{tabular}

Notes: a Corrected by Bonferroni procedure: 0.0I; SCID = Structured Clinical Interview DSM IV; ${ }^{\mathrm{b}} \mathrm{z}$-value $\leq-0.8$; ${ }^{\mathrm{c}}$ total score $\geq 20$; ${ }^{\mathrm{d}}$ total score $<24$. Abbreviations: SCID, Structured Clinical Interview for Diagnostic and Statistical Manual of Mental Disorders, Fourth Edition; SD, standard deviation. 
Table 4 Neuropsychological battery of tests

\begin{tabular}{|c|c|c|c|c|c|c|}
\hline $\begin{array}{l}\text { Test } \\
\text { (German version) }\end{array}$ & Domain & $\begin{array}{l}\text { Non-depressed (HADS) } \\
\text { z-value/score } \\
\text { M (SD) } \\
n=33\end{array}$ & $\begin{array}{l}\text { Depressed (HADS) } \\
\text { z-value/score } \\
M(S D) \\
n=13\end{array}$ & $\chi^{2}$ & df & $P$ value $^{a}$ \\
\hline $\begin{array}{l}\text { Trail Making Test A } \\
\text { (Zahlen-Verbindungs-Test) }\end{array}$ & $\begin{array}{l}\text { Attention, cognitive } \\
\text { and motor speed }\end{array}$ & $-0.26(0.62)$ & $-0.83(0.91)$ & 3.29 & I & 0.07 \\
\hline $\begin{array}{l}\text { Verbal Learning List } \\
\text { (Wortliste) }\end{array}$ & $\begin{array}{l}\text { Immediate and } \\
\text { delayed recall }\end{array}$ & 0.07 (1.01) & $0.42(0.80)$ & 0.98 & I & 0.32 \\
\hline $\begin{array}{l}\text { Digit Symbol Test } \\
\text { (Zahlen-Symbol-Test) }\end{array}$ & $\begin{array}{l}\text { Complex attention, } \\
\text { visuo-motor skills }\end{array}$ & $0.42(0.73)$ & $0.12(0.85)$ & 0.00 & I & 0.99 \\
\hline $\begin{array}{l}\text { Digit Recall } \\
\text { (Zahlennachsprechen) }\end{array}$ & $\begin{array}{l}\text { Memory, concentration, } \\
\text { concept formation }\end{array}$ & $0.43(0.87)$ & $0.31(1.22)$ & 0.96 & I & 0.33 \\
\hline $\begin{array}{l}\text { Cerebral Insufficiency Self Inventory } \\
\text { (Cerebrale-Insuffizienz-Skala) }\end{array}$ & $\begin{array}{l}\text { Subjective cognitive } \\
\text { impairment }\end{array}$ & I 6.8 (7.68) & I8.3 (6.64) & 0.10 & I & 0.75 \\
\hline
\end{tabular}

Note: ${ }^{\text {aC }}$ orrected by Bonferroni procedure: 0.01 .

Abbreviations: HADS, Hospital Anxiety and Depression Scale; SD, standard deviation.

in that our study revealed no significant differences regarding cognitive performance between patients with different CHF etiologies, such as dilated cardiomyopathy or coronary artery disease. Therefore, our first hypothesis was confirmed.

In contrast with the high overall rate of cognitive impairment in our sample, the MMSE could detect cognitive impairment in only $1.8 \%$ of the patients. This finding suggests that the MMSE might not be sensitive enough to diagnose minor or even moderate forms of cognitive impairment in patients with CHF. Altogether, our results are in line with earlier studies, which also found high rates of cognitive impairment in patients with CHF. Since these studies investigated mostly cognitive functioning in end-stage geriatric patients, they often reported even higher rates of cognitive

Table 5 Univariate and multivariate regression analysis: physical variables and depressive symptoms as predictors for objective and subjective cognitive impairment

\begin{tabular}{|c|c|c|c|c|}
\hline \multirow[t]{2}{*}{ Variable } & \multicolumn{2}{|c|}{$\begin{array}{l}\text { Subjective } \\
\text { cognitive } \\
\text { impairment }\end{array}$} & \multicolumn{2}{|c|}{$\begin{array}{l}\text { Objective } \\
\text { cognitive } \\
\text { impairment } \\
\end{array}$} \\
\hline & $\beta$ value & $P$ value & $\beta$ value & $P$ value \\
\hline \multicolumn{5}{|l|}{ Univariate } \\
\hline $\mathrm{pVO}_{2}(\mathrm{~mL} / \mathrm{min} / \mathrm{kg})$ & -0.19 & 0.41 & 0.20 & 0.16 \\
\hline LVEF (\%) & 0.24 & 0.11 & -0.17 & 0.25 \\
\hline 6-minute walk test $(\mathrm{m})$ & 0.01 & 0.95 & 0.069 & 0.64 \\
\hline $\begin{array}{l}\text { Depressive symptoms } \\
\text { (HADS) }\end{array}$ & 0.27 & 0.71 & 0.01 & 0.94 \\
\hline \multicolumn{5}{|l|}{ Multivariate } \\
\hline $\mathrm{PVO}_{2}(\mathrm{~mL} / \mathrm{min} / \mathrm{kg})$ & -0.25 & 0.15 & 0.39 & 0.04 \\
\hline LVEF (\%) & 0.33 & 0.04 & -0.13 & 0.45 \\
\hline 6-minute walk test $(\mathrm{m})$ & 0.13 & 0.44 & -0.12 & 0.51 \\
\hline $\begin{array}{l}\text { Depressive symptoms } \\
\text { (HADS) }\end{array}$ & 0.28 & 0.069 & 0.08 & 0.60 \\
\hline
\end{tabular}

Abbreviations: $\mathrm{PVO}_{2}$, peak oxygen uptake; LVEF, left ventricular ejection fraction; HADS, Hospital Anxiety and Depression Scale. impairment. ${ }^{15-17,36}$ In contrast with other studies, we investigated a middle-aged sample, and $56 \%$ of the patients were found to have objective or subjective impairment. This is quite surprising, given that we associate CHF mainly with elderly people.

Our study confirms the evidence of high prevalence rates of depressive symptoms in patients with $\mathrm{CHF}^{2,5}$ Using DSM IV criteria, the prevalence of current depression or dysthymia was $11.1 \%$. The self-report inventory, HADS, revealed a prevalence of clinically significant depressive symptoms of $25 \%$. These differences in prevalence rates are most likely due to depression assessment by either interview or self-report inventory. Assessing depressive symptoms by interview usually leads to lower prevalence rates compared with self-report inventories. ${ }^{2}$

Contrary to our expectation of a linkage between cognitive impairment and depressive symptoms in patients with CHF, there was no significant association between OCI or SCI and depressive symptoms (SCID, HADS). Similar results were found regarding quality of life. Because depressive symptoms and quality of life are overlapping variables, both were significantly related to each other, but neither depression nor quality of life was related to cognitive impairment, except for the correlation between SCI and the SF-36 subscale of General Health Perception. This finding is rather surprising, given that reciprocal enhancement could have been assumed.

Whereas the present pattern of results matches the results of previous studies, ${ }^{15,19,23,37}$ that is, depressive symptoms are unrelated to cognitive impairment in patients suffering from heart failure, the present data are also in conflict with those publications which found an association between depressive symptoms and cognitive 
impairment. ${ }^{14,38-41}$ It is conceivable that these conflicting findings are due to different samples (recruitment, sample size, age of patients) and to the different instruments to assess cognitive impairment, as well as due to the different methods used to evaluate depressive symptoms. For instance, in the investigation of Pullicino et al, ${ }^{38}$ the cognitive status of an older sample (mean age 64.7 years) was assessed only by one measure, ie, the six-item screener derived from the MMSE. In this population, there was a considerable rate of prior stroke compared with our study population which did not have a main diagnosis of vascular etiology. Lopez et $\mathrm{al}^{39}$ investigated a sample of older adults with mild cognitive impairment (mean age at least 74.0 years), of whom a significantly high percentage suffered from depression and had poor neuroradiological results, such as white matter lesions, cortical atrophy, and infarcts identified by magnetic resonance imaging. These vascular and neurodegenerative factors may have contributed to cognitive impairment in the sample reported by Lopez et al. As a consequence, it is difficult to compare this sample with our sample. Likewise, Thomas and $\mathrm{O}^{\prime} \mathrm{Brien}^{40}$ focused in their review mainly on depression in later life and mentioned the conflicting literature on whether depression is a risk factor for cognitive decline or not. Next, in their prospective longitudinal study, Barnes et $\mathrm{al}^{41}$ investigated a random sample of adults aged 65 years and older. Their results showed that worse depressive symptoms were associated with an increased risk of cognitive decline and dementia. These findings suggest that depressive symptoms in the absence of overt cognitive impairment may reflect early signs of neurodegenerative disease in older patients. Furthermore, an item overlap, eg, in the CES-D scale (statements that reflect aspects both of mood and cognition) has to be considered. To avoid item overlap with physical fatigue, for instance, which occurs due to heart failure, we used the HADS instrument. Because our sample consisted of middleaged patients diagnosed with dilated cardiomyopathy in $60 \%$ of cases, neurodegenerative and cerebrovascular aspects as a possible link between cognitive impairment and depression seem to play a less important role than in a sample of elderly patients. Regarding the somatic indicators of illness severity, our results revealed that cognitive impairment is more associated with reduced functional capacity than depression. In the final regression model, peak oxygen uptake was significantly related to OCI. Furthermore, SCI was related to LVEF. These results suggest that cognitive impairment might be secondary to deficits in blood supply in our sample. However, data concerning a relationship between LVEF and cognitive impairment are inconsistent. Whereas some studies ${ }^{22,23}$ found that neuropsychological scores were not related to cardiac output, others did find a relationship with LVEF. ${ }^{24}$

In summary, our data indicate that depression and cognitive impairment are independent comorbidities in middle-aged patients with $\mathrm{CHF}$. Further studies which also differentiate between OCI and SCI could be promising in clarifying this specific relationship and its underlying mechanisms. Our investigation has limitations that need to be taken into account, so the present pattern of results should not be overinterpreted. First, impaired cognitive functioning was classified as at least one cognitive measure out of the battery of neuropsychological tests falling below z scores $\leq-0.8$ (OCI), or/and showing a total score beyond the cutoff value of the Cerebral Insufficiency Self Report Inventory (SCI). Other researchers might apply different algorithms. Second, it is important to mention that, to the best of our knowledge, it is still a matter of debate as to which $\mathrm{z}$ score best reflects the onset of cognitive impairment. Third, it remains unclear which of the numerous instruments and measures reliably reflects cognitive impairment in this specific sample of middle-aged patients suffering from heart failure. As a consequence, future research should use alternative instruments to assess executive function.

Furthermore, the study was performed at a tertiary referral center. Therefore, the sample of patients with $\mathrm{CHF}$ as the main etiology does not represent typical patients with CHF seen by a general practitioner. These patients might show less impairment of LVEF and demonstrate a higher prevalence of coronary artery disease. ${ }^{42}$ Hence, our data may not be representative of patients in primary care or in the general population. It must also be pointed out that the cross-sectional design of the present study does not permit conclusions to be drawn concerning causality. However, the present data show a clear association between cognitive impairment and indicators of illness severity, whereas depressive symptoms and cognitive deficits do not show any association.

\section{Conclusion}

In this study, we found that CHF was associated with significant levels of cognitive impairment and depressive symptoms in a middle-aged sample of patients with NYHA functional class I-III disease, and whereas cognitive scores were significantly associated with peak oxygen uptake and LVEF, no significant association was found between cognitive impairment and depressive symptoms. Successful therapeutic management of CHF often depends heavily on the patient's understanding of and adherence to a complex medication regimen and a strict diet. Cognitive impairment, such as 
memory and attention difficulties, can be very problematic in this context because they might interfere with the patient's ability to adhere to medication and dietary therapies. Thus, cognitive impairment could possibly contribute to weakened compliance of patients with CHF with prescribed therapy and, as a consequence, increase the rate of hospital readmission. In light of the results of this study, reduced compliance in patients with depressive symptoms because of cognitive impairment seems highly unlikely. Physicians should be aware of these associations and be prepared to assess both the cognitive and affective state of patients in addition to physical parameters. However, even if the MMSE is largely applied in many clinical settings as the only instrument to assess cognition, it is not sensitive enough to identify mild or even moderate cognitive impairment in patients with CHF. Therefore caution is advised when the MMSE is applied as the sole measure to identify cognitive impairment in patients with CHF. Properly designed training programs to prevent, slow down, or cope with cognitive impairment, as well as implementation of depression screening programs in routine clinical practice could help to improve the treatment of patients with $\mathrm{CHF}$ and to prevent a progressive course of disease.

\section{Acknowledgment}

We thank Mark Brandes for data gathering and data entry. Moreover, we thank Anne-Louise Bornstein for proofreading the manuscript.

\section{Disclosure}

The authors report no conflicts of interest in this work.

\section{References}

1. Davis RC, Hobbs FDR, Lip GY. ABC of heart failure: history and epidemiology. BMJ. 2000;320:39-42.

2. Rutledge T, Reis VA, Linke SE, Greenberg BH, Mills PJ. Depression in heart failure: a meta-analytic review of prevalence, intervention effects, and associations with clinical outcomes. J Am Coll Cardiol. 2006;48: $1527-1537$.

3. Juenger J, Schellberg D, Mueller-Tasch T, et al. Depression increasingly predicts mortality in the course of congestive heart failure. Eur J Heart Fail. 2005;7:261-267.

4. Koenig HG. Depression in hospitalized older patients with congestive heart failure. Gen Hosp Psychiatry. 1998;20:29-43.

5. Juenger J, Schellberg D, Kraemer S, et al. Health related quality of life in patients with congestive heart failure: comparison with other chronic diseases and relation to functional variables. Heart. 2002;87: 235-241.

6. Jaagosild P, Dawson NV, Thomas C, et al; for SUPPORT investigators. The Study to Understand Prognosis and Preferences for Outcomes and Risks of Treatments. Outcomes of acute exacerbation of severe congestive heart failure: quality of life, resource use, and survival. Arch Intern Med. 1998;158:1081-1089.
7. Farmer ME. Cognitive deficits related to major organ failure: the potential role of neuropsychological testing. Neuropsychol Rev. 1994;4:117-160.

8. Bennett SJ, Sauve MJ. Cognitive deficits in patients with heart failure: a review of the literature. J Cardiovasc Nurs. 2003;18:219-242.

9. Woo MA, Kumar R, Macey PM, Fonarow GC, Harper RM. Brain injury in autonomic, emotional, and cognitive regulatory areas in patients with heart failure. J Card Fail. 2009;15:214-223.

10. Trojano L, Antonelli Incalzi R, Acanfora D, Picone C, Mecocci P, Rengo F. Cognitive impairment: a key feature of congestive heart failure in the elderly. $J$ Neurol. 2003;1456-1463.

11. Feola M, Rosso GL, Peano, M, et al. Correlation between cognitive impairment and prognostic parameters in patients with congestive heart failure. Arch Med Res. 2007;38:234-239.

12. Zuccala G, Marzetti E, Cesari M, et al. Correlates of cognitive impairment among patients with heart failure: results of a multicenter survey. Am J Med. 2005;118:496-502.

13. Pressler SJ. Cognitive functioning and chronic heart failure: a review of the literature (2002-July 2007). J Cardiovasc Nurs. 2008;23:239-249.

14. Bornstein RA, Starling RC, Myerowitz P, Haas GJ. Neuropsychological functioning in patients with end-stage heart failure before and after cardiac transplantation. Acta Neurol Scand. 1995;91:260-265.

15. Vogels RLC, Scheltens P, Schroeder-Tanka J, Weinstein HC. Cognitive impairment in heart failure: A systematic review of the literature. Eur J Heart Fail. 2007;9:440-449.

16. Bennett SJ, Sauve MJ, Shaw RM. A conceptual model of cognitive deficits in chronic heart failure. J Nurs Scholarsh. 2005;37:222-228.

17. Vogels RLC, Oosterman JM, van Harten B, et al. Neuroimaging and correlates of cognitive function among patients with heart failure. Dement Geriatr Cogn Disord. 2007;24:418-423.

18. Georgiadis D, Sievert M, Cencetti S, et al. Cerebrovascular reactivity is impaired in patients with cardiac failure. Eur Heart J. 2000; 21:407-413.

19. Woo MA, Macey PM, Fonarow GC, Hamilton MA, Harper RM. Regional brain gray matter loss in heart failure. J Appl Physiol. 2003;95:677-684.

20. Siachos T, Vanbakel A, Feldman DS, Uber W, Simpson KN, Pereira NL. Silent strokes in patients with heart failure. J Card Fail. 2005; $11: 485-489$.

21. Alves TC, Rays J, Fraguas R Jr, et al. Localized cerebral blood flow reductions in patients with heart failure: a study using $99 \mathrm{mTc}-\mathrm{HMPAO}$ SPECT. J Neuroimaging. 2005;15:150-156.

22. Zuccala G, Onder G, Pedone C, et al. Hypotension and cognitive impairment: selective association in patients with heart failure. Neurology. 2001;57:1986-1992.

23. Putzke JD, Williams MA, Daniel FJ, Foley BA, Kirklin JK, Boll TJ. Neuropsychological functioning among heart transplant candidates: a case control study. J Clin Exp Neuropsychol. 2000;22:95-103.

24. Almeida OP, Flicker L. The mind of a failing heart: a systematic review of the association between congestive heart failure and cognitive functioning. Intern Med J. 2001;31:290-295.

25. Strauss B, Thormann T, Strenge H, et al. Psychosocial, neuropsychological and neurological status in a sample of heart transplant recipients. Qual Life Res. 1992;1:119-128.

26. Oswald WD, Roth E. Trail Making Test A, Manual Handanweisung. Goettingen, Germany: Hogrefe; 1978. German.

27. Oswald WD, Fleischmann UM. Nuremberg Age Inventory (NAI). 3rd ed. Goettingen, Germany: Hogrefe; 1994. German.

28. Wechsler D. Wechsler Adult Intelligence Scale, WAIS, Manual. Bern, Germany: Huber; 1964.

29. Folstein MF, Folstein SE, McHugh PR. "Mini-Mental-State": a practical method for grading the cognitive state of patients for the clinician. J Psychiatr Res. 1975;12:189-198.

30. Weidenhammer W, Fischer B. C.I.-scale - a self-report inventory to evaluate mild cerebral insufficiency. Ebersberg, Germany: Vless; 1987. German. 
31. American Psychiatric Association. Diagnostic and Statistical Manual of Mental Disorders. Fourth Edition Text Revision. Goettingen, Germany: Hogrefe; 2000. German.

32. Wittchen, HU, Wunderlich U, Gruschwitz S, Zaudig M. Structured Clinical Interview for DSM IV Disorders (SKID I), Axis I: Psychiatric Disorders. Hogrefe, Goettingen: Hogrefe; 1997. German.

33. Zigmond AS, Snaith RP. The hospital anxiety and depression scale. Acta Psychiatr Scand. 1983;7:361-370.

34. Herrmann C. International experiences with the Hospital Anxiety and Depression Scale - a review of validation data and clinical results. J Psychosom Res. 1997;42:17-41.

35. Bullinger M, Kirchberger I. SF-36. Health Condition Inventory, Manual Handanweisung. Goettingen, Germany: Hogrefe; 1998. German.

36. Antonelli Incalzi R, Trojano L, Acanfora D, et al. Verbal memory impairment in congestive heart failure. J Clin Exp Neuropsychol. 2003;25:14-23.

37. Sauve MJ, Lewis WR, Blankenbiller M, Rickabaugh B, Pressler SJ. Cognitive impairments in chronic heart failure: a case controlled study. J Cardiac Fail. 2009;15:1-10.
38. Pullicino PM, Wadley VG, McClure LA, et al. Factors contributing to global cognitive impairment in heart failure: results from a populationbased cohort. J Cardiac Fail. 2008;14:290-295.

39. Lopez OL, Jagust WJ, Dulberg C, et al. Risk factors for mild cognitive impairment in the Cardiovascular Health Study Cognition Study: part 2. Arch Neurol. 2003;60:1394-1399.

40. Thomas AJ, O'Brien JT. Depression and cognition in older adults. Curr Opin Psychiatry. 2008;21:8-13.

41. Barnes DE, Alexopoulos GS, Lopez OL, Williamson JD, Yaffe K. Depressive symptoms, vascular disease, and mild cognitive impairment: findings from the Cardiovascular Health Study. Arch Gen Psychiatry. 2006;63:273-279.

42. Mosterd A, Hoes AW, de Bruyne MC, et al. Prevalence of heart failure and left ventricular dysfunction in the general population; The Rotterdam Study. Eur Heart J. 1999;20:447-455.
International Journal of General Medicine

\section{Publish your work in this journal}

The International Journal of General Medicine is an international peer-reviewed open-access journal that focuses on general and internal medicine, pathogenesis, epidemiology, diagnosis, monitoring and treatment protocols. The journal is characterized by the rapid reporting of reviews, original research and clinical studies across all disease areas.

\section{Dovepress}

A key focus is the elucidation of disease processes and management protocols resulting in improved outcomes for the patient.The manuscript management system is completely online and includes a very quick and fair peer-review system. Visit http://www.dovepress.com/ testimonials.php to read real quotes from published authors.

Submit your manuscript here: http://www.dovepress.com/international-journal-of-general-medicine-journal 